\title{
PIV investigation of high Reynolds number submerged water jets at high-pressure ambient conditions
}

\author{
Sarah Jasper $^{1}$ D $\cdot$ Jeanette Hussong ${ }^{2}$ D $\cdot$ Ralph Lindken $^{1}$ (D
}

Received: 27 July 2020 / Revised: 16 February 2021 / Accepted: 16 February 2021

(c) The Author(s) 2021

\begin{abstract}
High-pressure water jets bear a great technological potential to enhance geothermal deep drilling. Compared to existing water cutting technologies, significantly different operation conditions are encountered under deep-drilling conditions, such as high ambient pressures. The fundamental fluid mechanics are significantly affected by those operation conditions. In this work we examine the influence of increasing ambient pressure of up to $12.0 \mathrm{MPa}$ on the water jet characteristics under submerged drilling conditions. PIV measurements of the jet flow field at changing cavitation numbers reveal two characteristic regimes, which are distinguished by a critical cavitation number. In the cavitating regime, the jet decays considerably faster with increasing distance to the nozzle than in the non-cavitating regime. In addition to that, an increasing cavitation intensity shortens the potential core length of the water jet and increases the jet spreading angle and with this has a similar effect on the jet as increasing turbulence intensity in single-phase flows. Related to the decreasing kinetic energy of the jet in the cavitating regime, the resulting impact force of the water jet on the specimen surface decreases with increasing cavitation intensity. Our investigations indicate that a technology transfer from water jet cutting to submerged jet drilling requires adjustments of both nozzle geometries and jet operation conditions.
\end{abstract}

Sarah Jasper

sarah.jasper@hs-bochum.de

1 Institute for Thermodynamics and Fluid Mechanics, Bochum University of Applied Sciences, Bochum, Germany

2 Fluid Mechanics and Aerodynamics, Technical University of Darmstadt, Darmstadt, Germany 


\section{Graphic abstract}
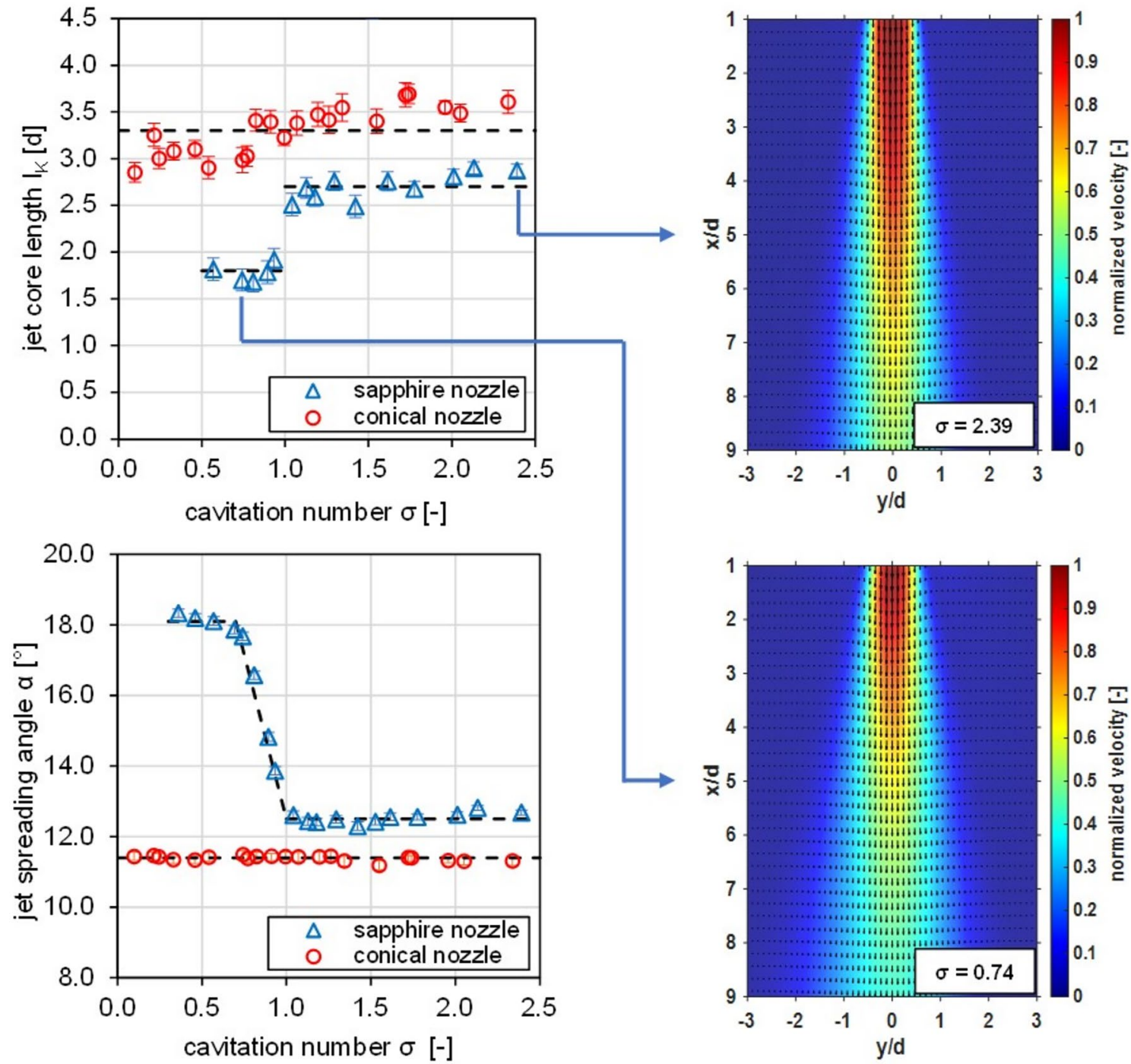

\section{Introduction}

High-pressure water jets are widely used in industry. One well-known technology is water jet cutting of various materials, which are processed by a focused liquid jet. In future, this technology shall be used more intensely in the field of deep drilling for diverse applications. In the oil and gas industry as well as in geothermal-related application this technology is known as jet drilling. Jet drilling is a costeffective drilling method which offers the possibility of a broader use of geothermal energy as a renewable energy resource. However, knowledge of the fundamental fluid mechanics is necessary to enable a successful technology

transfer. Therefore, investigations must take into account the different operating conditions. The jet drilling process is already used for enhancement of oil and gas recovery in non-crystalline rock formations such as sandstone in the oil and gas industry (Buset et al. 2001; Cinelli and Kamel 2013; Ragab and Kamel 2013). However, a transfer of the jet drilling process to low-permeable and crystalline rock formations, which are prevailing in geothermal reservoirs in several hundred metres depths, raises issues about the applicability.

Whereas water jet cutting is usually performed at nonsubmerged and atmospheric conditions, the jet drilling process is performed under submerged and pressurised 
conditions. This is because the ambient conditions during drilling, namely temperature and pressure, will increase with increasing depth. Ambient conditions will alter the fluid mechanics and with this the water jet properties which are crucial for the process. The impact of the pressure condition on the fluid mechanics of the jetting process itself is not well understood and therefore the focus of the present study.

Important fluid mechanical parameters for process characterisation are the available kinetic energy of the jet and the stagnation pressure. The kinetic energy of a jet increases with increasing velocity, and the stagnation pressure increases with increasing kinetic energy, which scales with the potential core length of the jet. The pressure profile of the stagnation pressure on a surface is known to be closely related to the velocity profile of the impinging jet, as, e.g., Leach et al. (1966) and Donaldson and Snedeker (1971) found in their experimental studies (Leach et al. 1966; Donaldson and Snedeker 1971). Therefore, a qualitative statement of the stagnation pressure can be made by evaluating the velocity profile of the jet. Furthermore, the resulting impact force on the rock surface increases with increasing kinetic energy and decreasing spreading angle of the impinging jet. Thus, the kinetic energy of the jet emerging from a nozzle and with this the velocity distribution, the jet spreading angle and the potential core length are quality measures for jet drilling.

Despite the high back pressure in a borehole, the occurrence of cavitation inside the applied nozzles is possible as the high-speed flow can easily cause cavitation during operation. Cavitation describes the process of nucleation in a fluid if the local pressure falls below the vapour pressure of the fluid (Young 1989; Brennen 1995). For nozzle flows as investigated here, hydraulic cavitation is of major interest. Hydraulic cavitation occurs due to a pressure drop inside the hydraulic system such as it is known from pumps or nozzles (Ross 2013). The cavitation number $\sigma$ is a measure of the extent of cavitation. Physically, the cavitation number describes the ratio of the available static pressure to the dynamic pressure of the flow.

$\sigma=\frac{p_{B}-p_{V}\left(T_{B}\right)}{1 / 2 \cdot \rho_{L} \cdot c_{L}^{2}}$

Here, $p_{B}$ denotes the back pressure and the vapour pressure is given as $p_{V}\left(T_{B}\right)$. It is a function of the ambient temperature. The fluid density $\rho_{L}$ and the fluid velocity $c_{L}$ contribute to the dynamic pressure. If the cavitation number is high, which means that the back pressure is significantly higher than the corresponding vapour pressure, nucleation and thus the occurrence of cavitation is unlikely. The higher the fluid velocity, i.e., the lower the cavitation number, the more probable is the occurrence of nucleation and cavitation. Each hydraulic system has its specific critical cavitation number below which nucleation starts.

For nozzle flows, the kinetic energy is determined by the pressure drop over the nozzle and the cavitation number can be rewritten as follows (Momma and Lichtarowicz 1995; Sou et al. 2007).

$\sigma=\frac{p_{B}-p_{V}\left(T_{B}\right)}{1 / 2 \cdot \rho_{L} \cdot c_{L}^{2}}=\frac{p_{B}-p_{V}\left(T_{B}\right)}{p_{N}-p_{B}}$

The occurrence of cavitation has a significant influence on the fluid mechanics. Therefore, cavitation has an influence on the emerging jet and therewith on the flow field of the jet. The mean flow field of free jets is already described in detail in literature, so only basic characteristics are recalled here (Martin 1977; Jambunathan et al. 1992; Pope 2000; Abramovich and Schindel 2003). In general, the flow field is distinguished into different regions. First, the jet emerges from the nozzle and enters the free jet zone. The diameter of the jet is related to the applied nozzle, and its diameter $\mathrm{d}$ and the velocity profile are in general turbulent. Then, the submerged jet enters the surrounding environment from which entrainment of mass, momentum and energy into the jet is caused by shear-driven interaction. Consequently, this mixing results in a widening of the jet and the jet spreading angle $\alpha$ increases. In this region of developing flow, the mixing layer surrounds a jet core where the centreline velocity is equal to the nozzle exit velocity. This so-called potential core extends from the nozzle exit and reaches up to the point, where the local centreline velocity falls below $95 \%$ of the nozzle outlet velocity (Martin 1977; Jambunathan et al. 1992). The potential core reduces in width with increasing shear layer and turbulence level. The region of developing flow is followed by a decaying jet region, where the centreline velocity continuously decreases, and the jet spreading angle continuously widens.

In the water jet cutting process, the kinetic energy of the jet per unit area is the power used to cut the workpieces. Consequently, a high jet velocity and a small jet spreading angle are favourable to ensure a high energy impact on the surface. Those jet parameters can be used to characterise the emerging jet and the influence of ambient conditions on the jet. This also helps to understand the jet drilling process under non-atmospheric conditions.

Most of the research related to jet drilling analyses the erosion effect of the water jet on the rock after the drilling process is finished. Furthermore, most experiments were conducted under atmospheric conditions at ambient pressure of 0.1 MPa. Different parameter studies varying the flow rate, stand-off distance between the high-pressure nozzle and the rock specimen, nozzle types and back pressure were conducted, i.e., (Brook and Summers 1969; Pols 1977; Hood et al. 1992; Liao et al. 2012; Dehkoda and 
Hood 2013; Reinsch et al. 2018). In general, the effective rock erosion decreases with increasing stand-off distance and increasing back pressure. In terms of fluid mechanics those parameters are comparable to an increasing jet spreading angle and a decreasing jet velocity if the nozzle pressure is kept constant. In summary, the effective rock erosion decreases with a decrease in available kinetic energy of the jet. Material and rock erosion are also promoted by cavitation (Momber 2004; Liao et al. 2012; Hutli et al. 2017). As an increased back pressure can lead to cavitation suppression, it is important to investigate whether there is a correlation between cavitation occurrence and rock erosion. For this, the actual jet drilling process needs to be analysed under in situ conditions, which is part of current investigation (Gradzki et al. 2018; Jasper et al. 2019).

In particular, the influence of fluid mechanic effects on the jet drilling process is not yet sufficiently understood. The operating conditions will have a significant effect on the performance as they affect the water jet emerging from the nozzle (Soyama et al. 1996; Jasper et al. 2017). As mentioned above, most of the rock drilling-related research has been conducted under atmospheric conditions, which means a water jet is injected into air at ambient pressure of $0.1 \mathrm{MPa}$. But both the surrounding fluid as well as the altered pressure conditions will have an influence on the fluid dynamics of the water jet, which had been initially neglected by those studies.

Matthujak et al. (2020) investigated the influence of water and air as surrounding fluid on different jet fluids (Matthujak et al. 2020). They found that the jet velocities in air were higher than in water, explained by lower aerodynamic forces compared to hydrodynamic forces. Jasper et al. (2017) showed that the spreading angle of a water jet in water is wider compared to that in air (Jasper et al. 2017). Higher shear forces at the jet boundary are the reason for this increase in the spreading angle. Thus, the jet drilling process should be analysed at submerged conditions to consider the different fluid properties and their influence on the emerging jet. For this reason, we examine the fluid mechanics of the jet drilling process under submerged conditions to quantify the influence on the drilling performance.

The influence of back pressure on the emerging water jet can be studied by utilizing the cavitation number and the jet parameters. A parameter study of various cavitation numbers conducted in this work represents various in situ drilling conditions.

In the present study, we perform PIV measurements to identify the effect of a submerged and pressurised environment on the development of a high-pressure water jet and the surrounding flow field.

\section{Experimental set-up}

The aim of the experiments is the investigation of the influence of in situ high-pressure drilling conditions on the fluid mechanics and the development of a water jet.

Three kinds of high-pressure nozzles are used for the experiments presented in this work. On the one hand, two sapphire-type nozzles with sharp-edged orifices are different in their geometry at the sapphire edge as they are from two different manufacturers. On the other hand, the third nozzle is a common convergent nozzle made of stainless steel. A section view of the tested nozzles is shown in Fig. 1, schematically illustrating the internal geometry and the nozzle body. Due to the nozzle designs the field of view of the PIV measurements is constraint to the optically accessible regions and starts at different axial distances $\mathrm{x} / \mathrm{d}$. Whereas the field of view of the conical nozzle $(\mathrm{CN})$ starts at $x / d=0$, the beginning for the sapphire-type nozzles is at $x / d=1$ for sapphire-type 1 (SN1) and $x / d=2$ for sapphire-type 2 (SN2), respectively. The smallest diameter is $d=1.8 \mathrm{~mm}$ for all three nozzles.

A quality measure of the jet drilling process is the available kinetic energy of the fluid jet and its distribution. Therefore, we examine the velocity distribution of the jet and in addition to that, the jet parameters such as the potential core length $l_{K}$ and the jet spreading angle $\alpha$. All these parameters can be analysed by optical measurements of the flow field. Those measurements are taken in a specially designed pressure vessel that is optically accessible.

The test bench is shown in Fig. 2. A pressure vessel designed for PIV experiments at back pressures up to 50 $\mathrm{MPa}$ and temperatures up to $40{ }^{\circ} \mathrm{C}$ is the central element of the test bench. The vessel has an inner diameter of 65 $\mathrm{mm}$, an inner height of $400 \mathrm{~mm}$ and a volume of $1.3 \mathrm{l}$. The nozzle is placed in the middle of the cross section at height position $120 \mathrm{~mm}$. Sensors are applied to measure the back

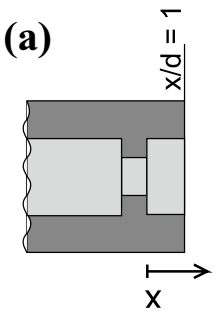

(b)

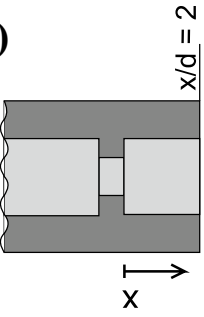

(c)

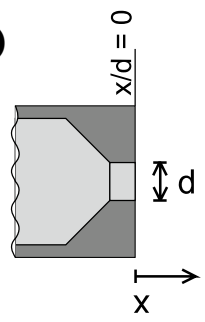

Fig. 1 Section view of the tested nozzles. Both sapphire-type nozzles (a) and (b) have a sharp-edged geometry at the smallest diameter. The conical nozzle (c) has a conical inflow towards the smallest diameter. The nozzle bodies are shown in dark colour and illustrate the constraints in the field of view for the PIV experiments 


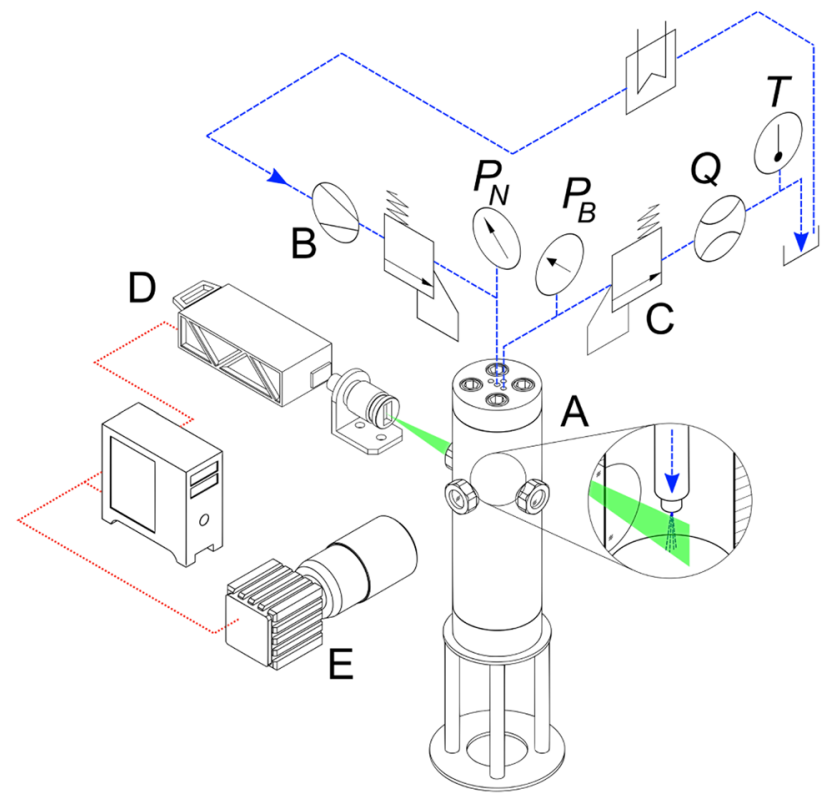

Fig. 2 Hydraulic flow scheme of the test bench with pressure vessel (A), high-pressure pump (B), sensors (flow Q, pressures $\mathrm{P}_{\mathrm{N}}$ and $P_{B}$, temperature $T$ ) and needle valve (C). The optical set-up for PIV analysis with laser (D) and camera (E) is also illustrated, not to scale

pressure $p_{B}$, the nozzle pressure $p_{N}$, the flow rate $Q$ and the temperature $T$, as indicated in Fig. 2. The nominal accuracy of the applied sensors is $\pm 0.3 \%, \pm 2 \%$ and $\pm 2.5{ }^{\circ} \mathrm{C}$ of the actual value for the pressure sensors, the flow sensor and the temperature sensor, respectively. The water jet is generated by a high-pressure plunger pump with a maximum outlet pressure of $20 \mathrm{MPa}$ and a maximum flow rate of $54 \mathrm{ll}$ $\mathrm{min}$. The pump supply is from a settling chamber at ambient pressure with a volume of $200 l$. The flow rate of the plunger pump is stabilised by a pressure accumulator. The nozzle outlet pressure is regulated by a pneumatic valve at the pump outlet. Regulation of the flow rate and the back pressure in the vessel is realised by a needle valve at the outlet of the vessel. A constant temperature level of $39{ }^{\circ} \mathrm{C}$ in the water circuit is ensured by a 7-kW cooling unit attached to the settling chamber.

The vessel offers optical access by three sapphire windows with a clear aperture of $35 \mathrm{~mm}$, positioned in a $90^{\circ}$ angle each. Two of those windows are used to perform PIV measurements. The third window is for shadowgraph experiments and is not used in this measurement campaign (Jasper et al. 2017). The PIV system consists of a 16-bit sCMOS camera (LaVision, sCMOS, $2550 \times 2160$ pixels) with a Zeiss Yashica macro lens equipped with a bandpass filter and a Nd:YAG double-pulse laser (Quantel Evergreen 200, repetition rate $15 \mathrm{~Hz}$ ), which are synchronised by a timing unit. To avoid laser light reflections on the nozzle and the inner wall of the vessel, fluorescent tracers with an average diameter
Table 1 Overview of experimental parameters

\begin{tabular}{llll}
\hline Pressure difference & 5.0 & & $\mathrm{MPa}$ \\
Nozzle pressure & $5.6-17.0$ & $\pm 0.3 \%$ & $\mathrm{MPa}$ \\
Back pressure & $0.7-12.0$ & $\pm 0.3 \%$ & $\mathrm{MPa}$ \\
Cavitation number & $0.33-2.39$ & & - \\
Flow rate & $13.5-15.0$ & $\pm 2 \%$ & $1 / \mathrm{min}$ \\
Reynolds number & $163,000-180,000$ & & - \\
\hline
\end{tabular}

of $10 \mu \mathrm{m}$ and an emission peak at $560 \mathrm{~nm}$ are used. The use of fluorescent tracers also minimises reflections at the interface of occurring cavitation bubbles. The recorded images have a dimension of $14.0 \times 16.4 \mathrm{~mm}$ with a scaling factor of $6.4 \mu \mathrm{m} /$ pixel. A time interval between two recordings of 1 $\mu$ s has been chosen resulting in a displacement of 15 pixel in the core region of the jet. For PIV analysis, a multi-pass decreasing interrogation window is applied. Initial window size of $64 \times 64$ pixels is calculated once followed by a final window size of $32 \times 32$ pixels which is calculated twice with an overlap of $50 \%$. The corresponding number of vectors in the ROI is $135 \times 160$, resulting in a spatial resolution of a vector each $100 \mu \mathrm{m}$. Universal outlier detection with rejection of vectors exceeding a difference to the average of twice the standard deviation of the nearest neighbours is used for error analysis (Westerweel and Scarano 2005). The outcomes are averaged over 1000 statistically independent recordings resulting in an accuracy of the averaged velocities of $99 \%$ and an accuracy of the rms values of the velocity of $90 \%$. The statistical convergence of the average velocity field is tested at the centreline of the jet at the nozzle outlet and results in a convergence of the data from 1000 frames, and details are given in supplementary material.

To identify the influence of changing in situ conditions on the water jet, experiments are conducted with a constant pressure drop over the nozzle of $5 \mathrm{MPa}$ and at different cavitation numbers. The range of cavitation numbers represents the pressure ratio between the back pressure inside the borehole and the pressure drop over the nozzle. Thus, the cavitation number resembles changing pressure conditions due to different drilling depths. An overview of the experimental parameters is given in Table 1. Independence of the results from the installation was tested by ten different repeated measurements at the same experimental parameters.

\section{Results}

The influence of pressure conditions during jet drilling on characteristics of a submerged water jet is presented in the following. The occurrence of cavitation of a submerged, high-velocity fluid jet is examined as a function of changing ambient conditions resembling pressure conditions during 
a drilling process. Hence, averaged velocity fields as well as the relevant jet parameters that dominate waterjet-driven drilling processes, are analysed.

\subsection{Cavitation inside nozzles}

Cavitation plays an important role in the investigation of in situ conditions on a water jet with changing ambient conditions. While operating at the same pressure level at the nozzle outlet, the ambient pressure conditions change while drilling at increasing depths such that the cavitation number increases, and at some point, cavitation is suppressed. In our study we investigate the cavitation state which leads to choked flow. This cavitation state can easily be studied by analysing the resulting flow rate for given pressure levels (Ebrahimi et al. 2017; Jasper et al. 2019). A cavitationinduced choking condition is therefore associated with a flow rate independence of the applied pressure. At this condition, the flow rate reaches a maximum, whereas it is assumed that no cavitation is present in the case of the flow rate dependence on the pressure. This behaviour is shown in Fig. 3 for three different nozzles types and different operating pressures. The back pressure is continuously increased by gradually closing the needle valve at the pressure vessel outlet, while the nozzle outlet pressure is kept constant. The resulting normalised flow rate is then plotted over the cavitation number. The cavitation behaviour of different nozzles at the same applied nozzle outlet pressure is shown in Fig. 3a. The different sapphire-type nozzles with same overall design and smaller geometry variations show the same behaviour. Below a critical value of $\sigma_{\text {crit }}=1.0$ cavitation-induced choking occurs as can be seen from the constant flow rate. Above this critical value, the flow rate decreases with increasing cavitation number and thus no cavitation effect in the nozzle can be observed. In contrast to the sapphire-type nozzles, the conical nozzle shows no choked flow and thus no cavitation occurs inside the nozzle. This is in good agreement with previous studies (Ohrn et al. 1991; Payri et al. 2002; Macian et al. 2003). Moreover, the onset of cavitation for a specific nozzle is not dependent on the applied pressure level but only on the cavitation number. This is indicated in Fig. 3b, where nozzle outlet pressures of up to $30 \mathrm{MPa}$ are applied for sapphire-type nozzle SN1.

\subsection{Averaged velocity fields, potential core length and jet spreading angle}

Exemplary averaged velocity fields of SN1 and CN nozzles, as shown in Fig. 1, are presented in Fig. 4. Velocity fields for SN2 are not further examined as this nozzle shows the same characteristics as SN1, but has a more restricted optical access. The complete data set for all examined cavitation numbers and nozzles is given in supplementary material of this article, represented as 2D velocity fields. Figure $4 a, b$ presents velocity fields in the non-cavitating regime of nozzles SN1 and CN, respectively. Figure 4c, d shows velocity field in the cavitating regime of nozzle SN1 and at comparable cavitation number for nozzle $\mathrm{CN}$, respectively. Note that due to the optical constraints inside the field of view by the nozzle bodies the velocity fields do show an overlapping region in the range of $1 \leq x / d \leq 9$, whereas for $x / d<1$ and $x / d>9$ some comparable data are not available. The averaged velocity fields of $\mathrm{CN}$ presented in Fig. $4 \mathrm{~b}$ and $\mathrm{d}$ show no significant changes with decreasing cavitation number. In contrast to that, the cavitation number has a notable influence on the averaged velocity fields of SN1. With decreasing the cavitation number from $\sigma=2.39$ to $\sigma=0.74$ the nozzle flow changes from the non-cavitating to the cavitating regime. When entering the cavitating regime by decreasing the cavitation number to $\sigma=0.74$, the zone of high velocities, the potential core, shortens noticeably.

To further evaluate the development and decay of the water jet, potential core length, spreading angle and velocity profiles are examined as a function of cavitation number in the following. The jet parameters and velocity profiles are
Fig. 3 Cavitation behaviour of three different nozzles at operating pressure $10 \mathrm{MPa}(\mathbf{a})$ and cavitation behaviour of the sapphire-type nozzle SN1 shown for different nozzle outlet pressures (b)
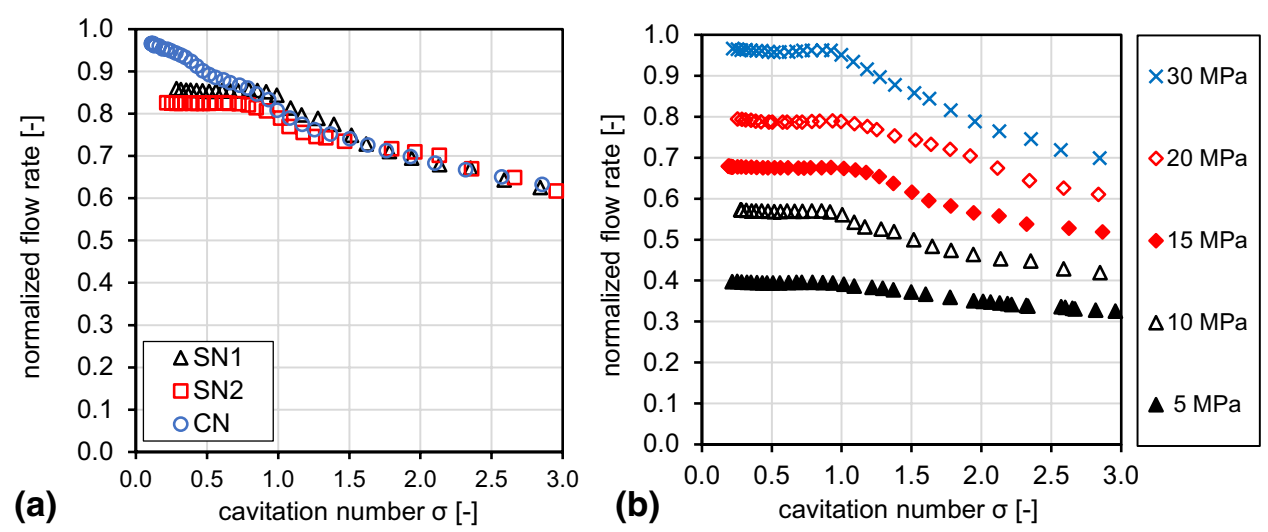
Fig. 4 Time-averaged velocity fields over 1000 instantaneous PIV measurements, normalised velocity is colour coded and velocity components are shown as vectors. Velocity fields of SN1 nozzle are shown in the non-cavitating regime at $\sigma=2.39$ (a) and the cavitating regime $\sigma=0.74(\mathbf{c})$, respectively. Additionally, velocity fields of $\mathrm{CN}$ nozzle at comparable cavitation numbers of $\sigma=2.34$ (b) and $\boldsymbol{\sigma}=0.74(\mathbf{d})$ are displayed
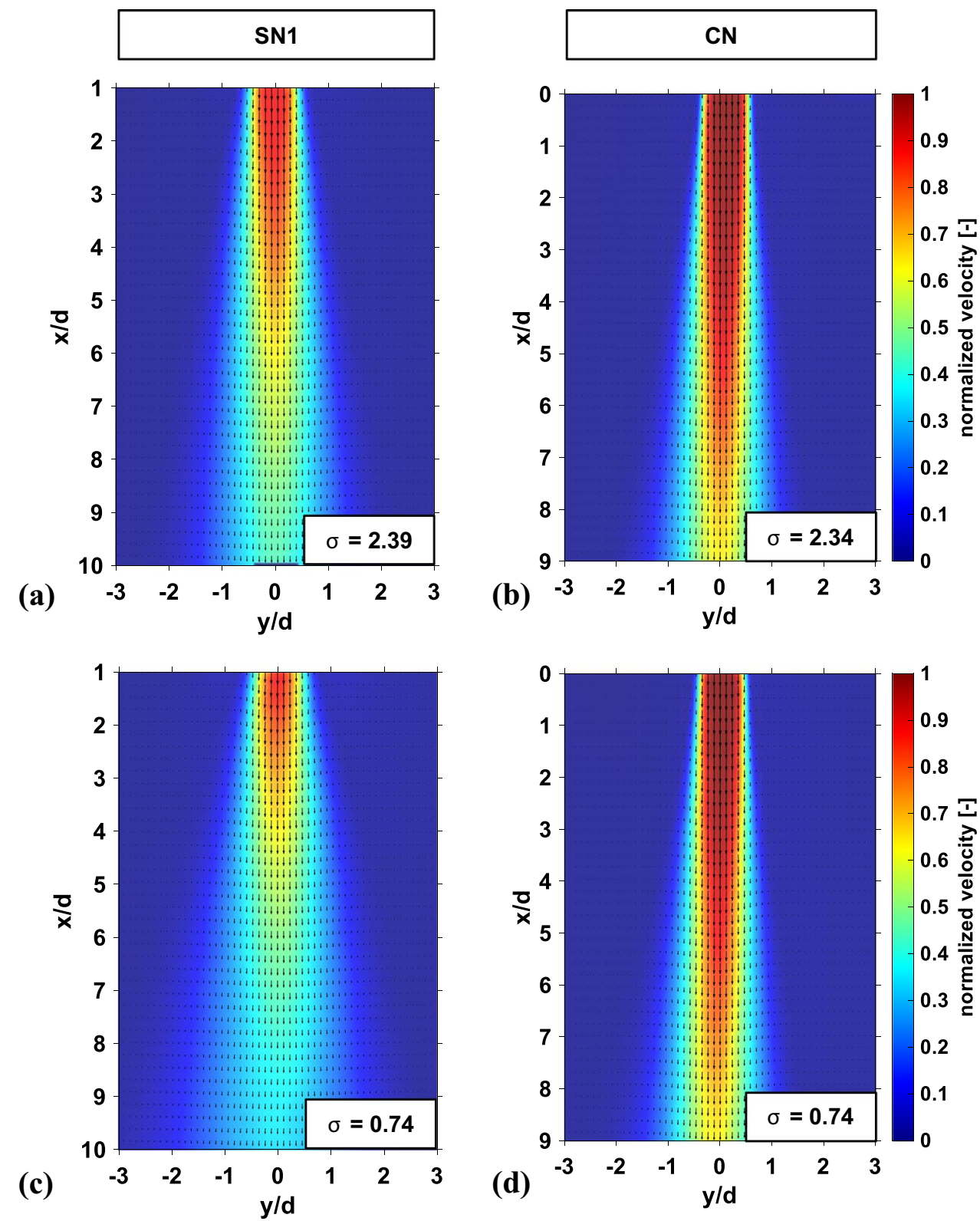

examined for SN1, as example for sapphire-type nozzles, and $\mathrm{CN}$ in the following. Figure 5 gives a schematic sketch of the analysed jet parameters.

The potential core length is estimated as the length of the streamwise centreline velocity beginning from the jet exit until the local centreline velocity drops below $95 \%$ of the jet exit velocity $\mathrm{u}_{\max }\left(0.95 u_{\max }\right)$. A sensitivity analysis of our data reveals that changing the thresholds from 0.99 $u_{\max }$ to $0.96 u_{\max }$ increases the potential core length by more than $20 \%$, while a change from 0.95 to $0.90 u_{\max }$ produces approximately $5 \%$ increase in the potential core length. The threshold of $95 \%$ of the jet exit velocity is a reasonable estimation here and is also in accordance with other studies
(Martin 1977; Jambunathan et al. 1992). A comparison of the core lengths of both nozzle types is given in Fig. 6a.

The values of the core length $l_{\mathrm{K}}$ of SN1 as multiples of the nozzle diameter $\mathrm{d}$ are in the range of $1.7 \mathrm{~d}<l_{\mathrm{K}}<2.9 \mathrm{~d}$. Two different regions can be identified in Fig. 6a. If the cavitation number is higher than the critical cavitation number, the average value of the core length is $2.7 \mathrm{~d}$. For lower cavitation numbers the average value of the core length is $1.8 \mathrm{~d}$. The core length is generally depending on the internal velocity profile and turbulence inside the nozzle (Carlomagno and Ianiro 2014). The influence on cavitation-induced choked flow is clearly visible as the turbulence induced by cavitation results in a shortening of the core length. In contrast to SN1, 


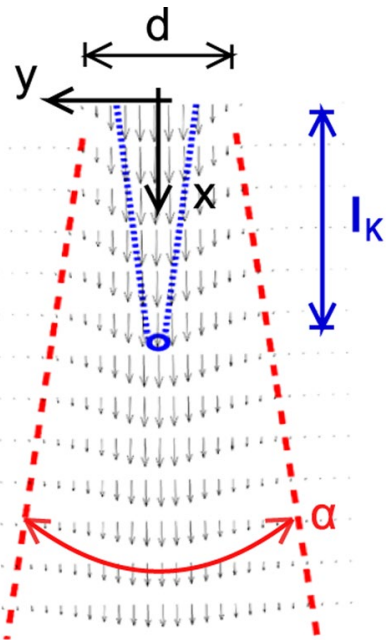

Fig. 5 Sketch of the analysed jet parameters. The coordinates are given as follows, $x$ depicts the streamwise or axial coordinate and $y$ depicts the radial coordinate. Exemplary, the potential core length $l_{K}$ is indicated as well as the spreading angle $\alpha$ and the nozzle outlet diameter $d$

the core lengths of $\mathrm{CN}$ reveal an almost constant value of $3.3 \mathrm{~d}$. This result is expected as no cavitation occurs inside the nozzle. From the values of the core lengths, it can be seen that the velocity decay on the centreline of $\mathrm{CN}$ is less than that of the sapphire-type nozzle.
In addition to the potential core, the jet spreading angle is estimated in radial direction when the local velocity drops below $10 \%$ of the centreline velocity at the same axial distance. A sensitivity analysis of the data shows no significant change in the results for thresholds from 5 to $15 \%$. The spreading angle of the two nozzle types is plotted in Fig. $6 \mathrm{~b}$ as a function of cavitation number. The spreading angle of $\mathrm{SN} 1$ is in the range of $12.3^{\circ}<\alpha<18.3^{\circ}$. Above the critical cavitation number, the average spreading angle is $12.5^{\circ}$. In the range of $0.70<\sigma<1.00$, the spreading angle increases linearly from $12.5^{\circ}$ to $18.3^{\circ}$ and below $\sigma=0.67$ the average spreading angle is $18.3^{\circ}$. Again, in contrast to the spreading angle of SN1, CN shows an almost constant spreading angle of $11.4^{\circ}$ over the investigated range of cavitation numbers.

Depending on the cavitation number, cavitation bubbles do not only exist inside the nozzle but also reach outside the nozzle. Time-averaged inverted bright field images of nozzle SN1 at cavitation numbers from $\sigma=0.25-1.50$ are presented in Fig. 7. The nozzle body is shown at the top of each image, and dark areas below the nozzle present cavitation areas. With increasing cavitation number, the cavitation area shortens from $x / d=3.5$ to 0 , as cavitation intensity becomes lower. Therefore, the bright field images reveal that a decreasing cavitation number causes the cavitation to expand even behind the nozzle body. Although cavitation occurs below $\sigma_{\text {crit }}=1.00$, no cavitation bubbles are visible in Fig. 7 for $\sigma=1.00$. This is because the field
Fig. 6 Potential core length (a) and spreading angle (b) of both $\mathrm{SN} 1$ and $\mathrm{CN}$ as a function of cavitation number
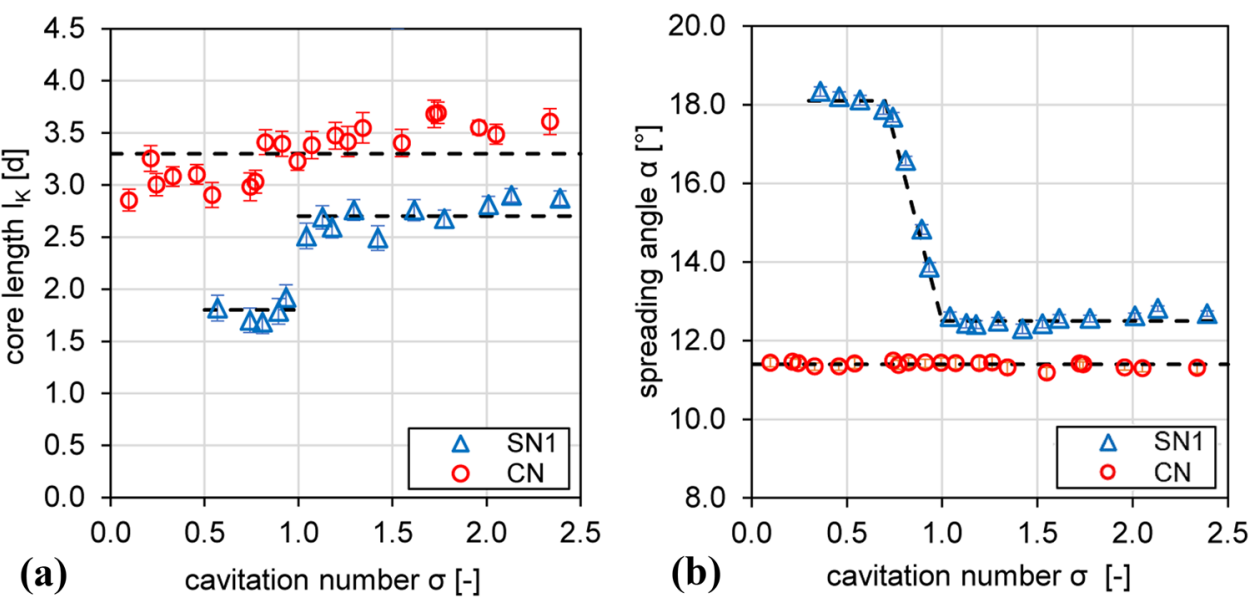

Fig. 7 Time-averaged bright field images of SN1 at cavitation numbers in the range from $\sigma=0.25-1.50$. The inverted images show cavitation areas as black coloured, whereas the surrounding water is in light colour

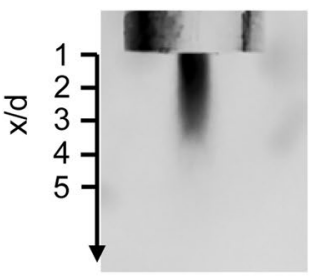

$\sigma=0.25$

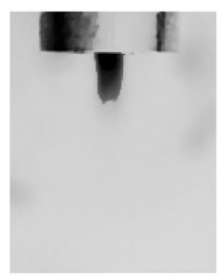

$\sigma=0.43$

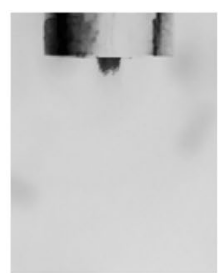

$\sigma=0.67$

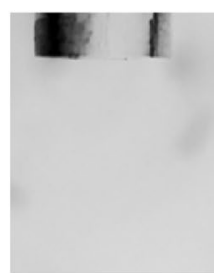

$\sigma=1.00$

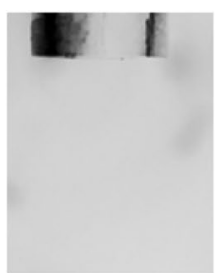

$\sigma=1.50$ 
Fig. 8 Normalised centreline velocity profiles of SN1 (a, $\Delta)$, SN2 $(\mathbf{b}, \square)$ and $\mathrm{CN}(\mathbf{c}, \bigcirc)$ and a comparison of all three nozzles (d). The velocity profiles are shown at the cavitation numbers indicating the noncavitating regime $(\sigma>1.00)$, close to the critical cavitation number $(\sigma=1.00)$ and in the cavitating regime $(\sigma<1.00)$ of nozzle SN1 (a)

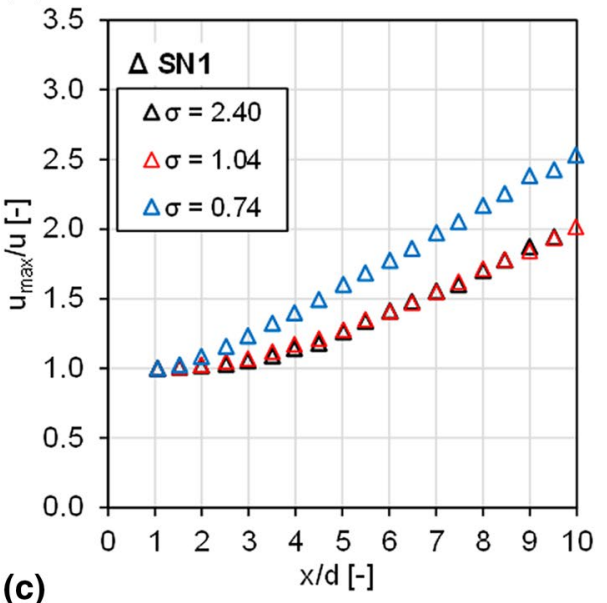

(c)
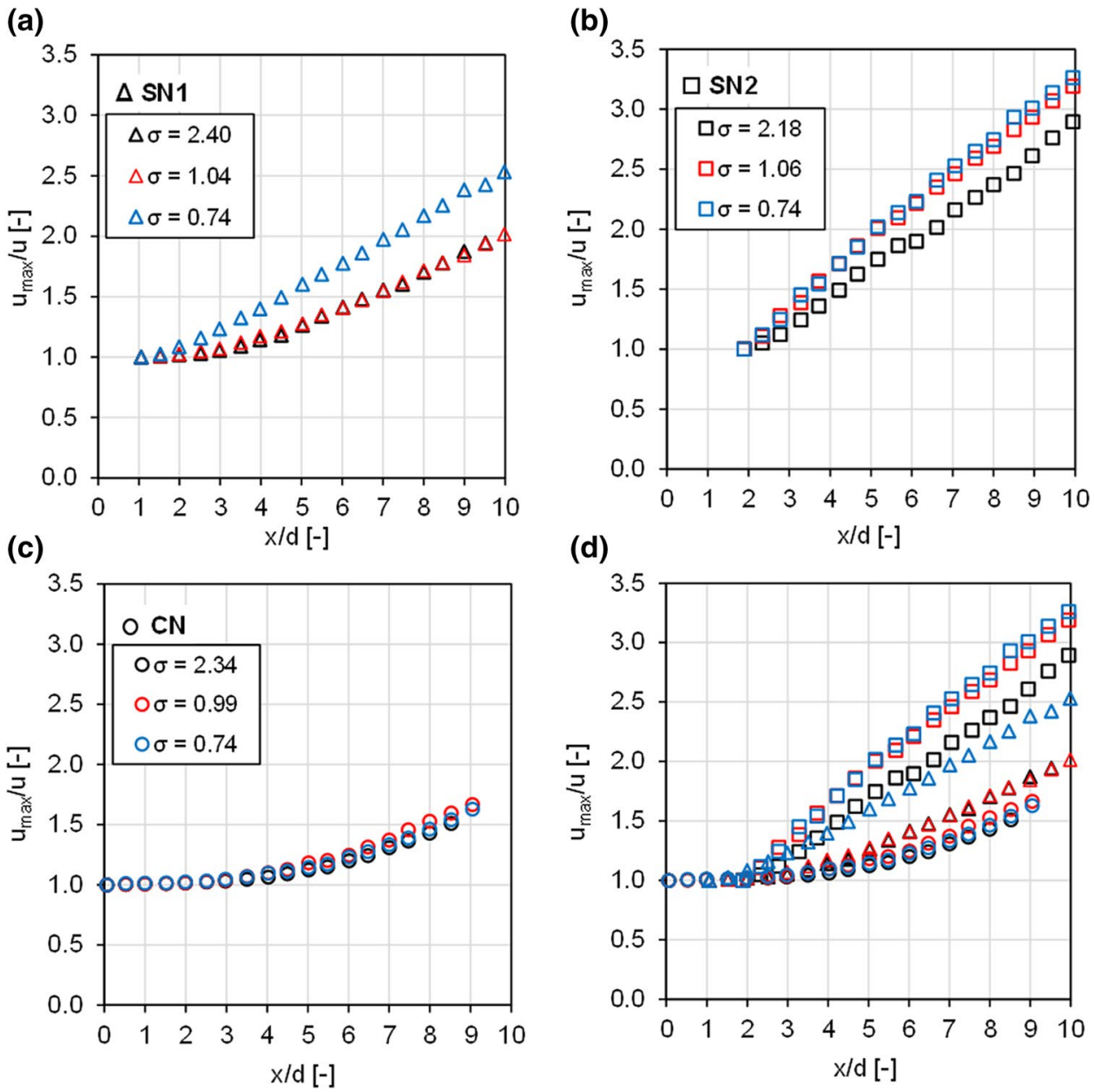

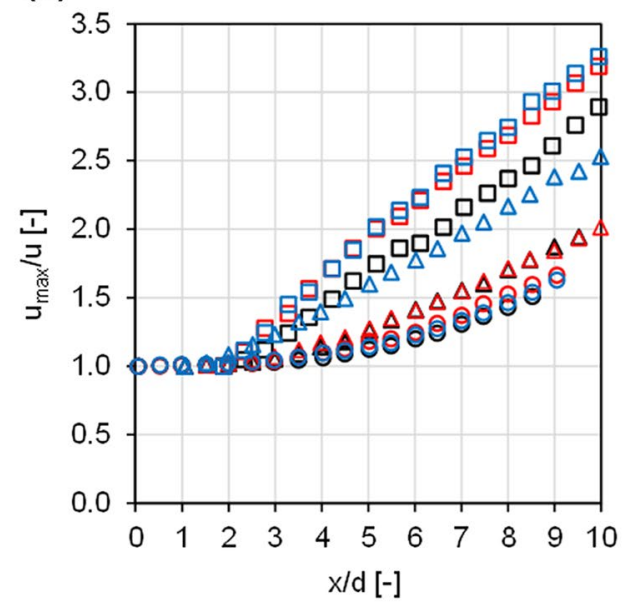

of view starts at $x / d=1$ due to the geometrical constraint of the nozzle body explained in the experimental set-up. We assume that the cavitation bubbles formed at this condition might have been imploded until $x / d=1$. The intensity of cavitation, i.e., the density of cavitation bubbles, seems to have no significant effect on the potential core lengths. Once cavitation occurs at a critical cavitation number of $\sigma_{\text {crit }}=1.00$, the potential core length rapidly drops from 2.7 to $1.8 \mathrm{~d}$. While the critical cavitation number for the sudden change in the core length is $\sigma_{\text {crit }}=1.00$, the jet spreading angle shows a rather gradual change. The jet spreading angle starts to increase at $\sigma=1.00$ until a constant value is reached below $\sigma=0.67$. This is exactly the region where the cavitation bubbles do not expand behind the body of the nozzle. The limited space inside the nozzle right behind the sapphire insert inhibits the jet expansion although the cavitation bubbles already implode in this region.

Analysing both the potential core lengths and spreading angles as a function of cavitation number, a significant influence of cavitation on those jet parameters can be identified. Our experiments show that an increasing cavitation intensity, i.e., a decreasing cavitation number, has similar effect on the potential core length and jet spreading angle as it is known for jets with an increasing turbulence intensity in singlephase flows (Gauntner et al. 1970; Carlomagno and Ianiro 2014). Increasing cavitation intensity leads to a shortening of the potential core length and an increase in the jet spreading angle. The presence of cavitation causes an increased jet decay and widening of the jet due to the unsteady bubble collapse. According to Sou et al. and Örley et al. this leads to strong turbulent velocity fluctuations inside the water jet (Sou et al. 2007; Örley et al. 2015). To better understand the interaction between cavitation and the turbulence characteristics of the flow, an analysis on the turbulent kinetic energy is performed in Sect. 3.3.

\subsection{Jet decay, velocity profiles and turbulent kinetic energy}

In addition to the potential core length and the spreading angle, the decay of the streamwise centreline velocity is examined as a function of cavitation number. The jet decay is used here as a qualitative measure to assess the degree of 
Table 2 Decay rates $\mathrm{K}_{\mathrm{d}}$ as a function of cavitation number for the examined nozzles

\begin{tabular}{llll}
\hline Nozzle & $\sigma$ & $K_{d}$ & Range \\
\hline SN1 & 2.39 & 0.141 & $3 \leq x / d \leq 10$ \\
& 1.53 & 0.132 & \\
& 1.13 & 0.137 & \\
& 1.04 & 0.138 & \\
& 0.93 & 0.153 & \\
& 0.89 & 0.161 & \\
& 0.81 & 0.180 & $3 \leq x / d \leq 10$ \\
& 0.74 & 0.188 & \\
SN2 & 0.69 & 0.189 & $3.5 \leq x / d \leq 9$ \\
& 2.23 & 0.244 & \\
CN & 1.08 & 0.267 & \\
& 0.74 & 0.265 & \\
& 2.34 & 0.097 & \\
& 1.00 & 0.112 & \\
\hline
\end{tabular}

entrainment and mixing characteristics of the turbulent jet. The effect of cavitation number on the streamwise velocity decay is shown in Fig. 8. In the potential core region, the maximum outlet velocity normalised by the centreline velocity $\left(u_{\max } / u\right)$ is self-similar and nearly constant for each nozzle. Downstream of that region, the velocity decay is nearly linear and can be estimated by the following relation, where $K_{d}$ and $x_{0}$ are the decay rate and the kinematic virtual origin, respectively (Quinn and Militzer 1988):

$\frac{u_{\max }}{u}=K_{d} \cdot\left(\frac{x}{d}-\frac{x_{0}}{d}\right)$

According to the given relation, the decay rate $\mathrm{K}_{\mathrm{d}}$ is evaluated by fitting least-square lines to the velocity profiles. The values of $\mathrm{K}_{\mathrm{d}}$ and their applied range are given in Table 2. The decay rates of SN1 show an almost constant value in the non-cavitating regime. Below the critical cavitation number $\sigma_{\text {crit }}=1.00$, the decay rate starts to increase from $K_{d}=0.137$ up to $K_{d}=0.180$ at $\sigma=0.81$ in the transition regime. With further decrease in cavitation number the cavitation-induced choking regime is reached and the decay rate shows again an almost constant value of $K_{d}=0.188$. This is an increase in decay rate of about $32 \%$ in comparison with the non-cavitating regime at $\sigma=2.39$. It shows that cavitation occurrence has a strong influence on the jet decay. The increase in velocity decay is also illustrated by the increasing slope of the velocity profiles in Fig. 8a. SN2 shows the same increase in decay rate from the non-cavitating to the cavitating regime, but with $11 \%$ the increase is less. Although both sapphire-type nozzles belong to the sharp-edged nozzle types, a slight difference at the detailed geometry of the sapphire insert itself can cause different nozzle behaviour. The values of the decay rate itself are apparently higher than for SN1, which becomes evident from a steeper slope of the velocity profiles in Fig. 8b. In comparison with the sapphiretype nozzles, $\mathrm{CN}$ shows an almost constant decay rate of $K_{d}=0.104$, which is also smaller than the decay rates of both sapphire-type nozzles. The slope of the velocity profiles is remarkably smaller as depicted in Fig. 8c. These findings suggest that the influence of in situ drilling conditions and their changing ambient pressure conditions have a greater impact on the sapphire-type nozzle performance than on the conical nozzle performance as cavitation occurs at smaller cavitation numbers for those nozzles. Nevertheless, in practical applications sapphire-type nozzles are preferred due to their longer lifetime.

A more detailed examination of the transition from the non-cavitating to the cavitation-induced choking regime and its influence on the jet is given by the decay of the centreline velocity of the SN1 for different cavitation numbers, shown in Fig. 9. For the sake of clarity, only the cavitation numbers below $\sigma=1.13$ are shown. The velocity profiles of higher cavitation numbers coincide with the velocity profiles of $\sigma=1.13$ and $\sigma=1.03$. Above the critical cavitation number of $\sigma_{\text {crit }}=1.00$ the velocity profiles are nearly identical and have an almost constant decay rate. Below $\sigma_{\text {crit }}=1.00$, there is a transition regime where the slope of the velocity profile declines with further decreasing cavitation number until $\sigma=0.81$. Along with a further decreasing cavitation number below $\sigma=0.81$ the velocity profiles are again nearly identical. This transition regime of the decay rates shows similarities to the characteristics of the spreading angle. In the non-cavitating and the cavitating regime a constant value for each jet parameter is given, respectively. Both values are linearly connected in the transition regime for cavitation

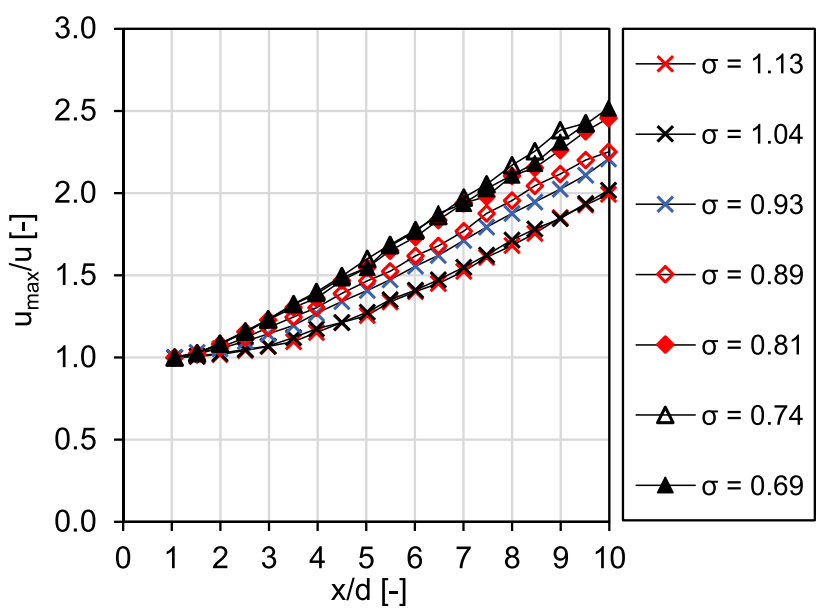

Fig. 9 Normalised centreline velocity profiles of $\mathrm{SN} 1$ at cavitation numbers from $\sigma=0.69-1.13$ in the transition range 
Fig. 10 Normalised radial velocity distribution at $x / d=1.5-6$ of SN1 nozzle at cavitation numbers in the range of $\sigma=0.57-2.39$
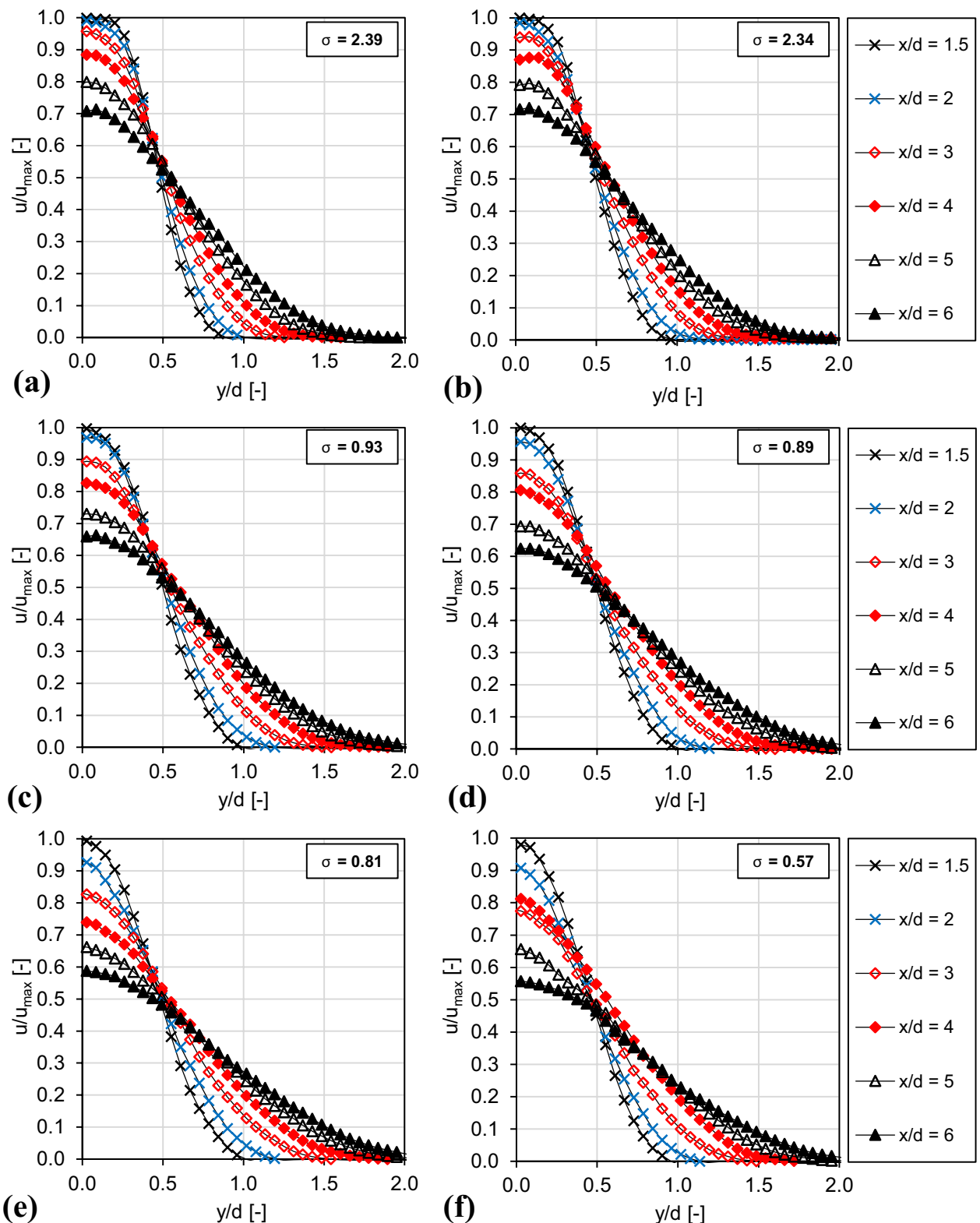

numbers of $\sigma=0.67-1.00$, as also shown in Fig. $6 \mathrm{~b}$. These are the cavitation numbers at which the cavitation bubbles expand from inside the nozzle body to the outside.

This transition from the cavitating to the non-cavitating regime also affects the radial velocity distribution. Again, for SN1, Fig. 10 illustrates the radial velocity distribution at different axial distances $x / d=1.5-6$ at cavitation numbers in the range of $\sigma=0.57-2.39$. Figure $10 \mathrm{a}$ and $\mathrm{b}$ show the non-cavitating regime, in which the radial velocity distribution in the near-nozzle region shows a typical saddle-back shape which merges into a Gaussian-shape distribution with increasing axial distance x/d (Martin 1977; Pope 2000; Abramovich and Schindel 2003). The jet widening is also clearly visible as the velocity distribution becomes flatter.
The transition regime presented in Fig. 10c and d does not show a saddle-back shape in the near-nozzle region but an almost Gaussian-shape velocity distribution. Due to the influence of imploding cavitation bubbles the common jet development is disrupted. With increasing axial distance, the velocity distribution flattens faster than in the non-cavitating regime, which is related to the faster jet decay in this regime. After the transition regime, the velocity profiles show only a marginal difference to further decreasing cavitation numbers as illustrated in Fig. 10e and f.

Figure 11 presents the radial velocity distribution at axial distances from $x / d=1.5-6$ of SN1 and CN for the non-cavitating and cavitating regime, respectively. In the near-nozzle region, the radial velocity profile from the jet issuing from 
Fig. 11 Normalised radial velocity distribution at $x / d=1.5-6$ for $\mathrm{SN} 1$ and $\mathrm{CN}$ nozzles in the non-cavitating $(\sigma=2.39)$ and cavitating regime $(\sigma=0.74)$

Fig. 12 Normalised radial velocity distribution and turbulent kinetic energy of SN1 for indicated cavitation numbers of $\sigma=0.57-2.39$ at axial distance of $x / d=1.5$
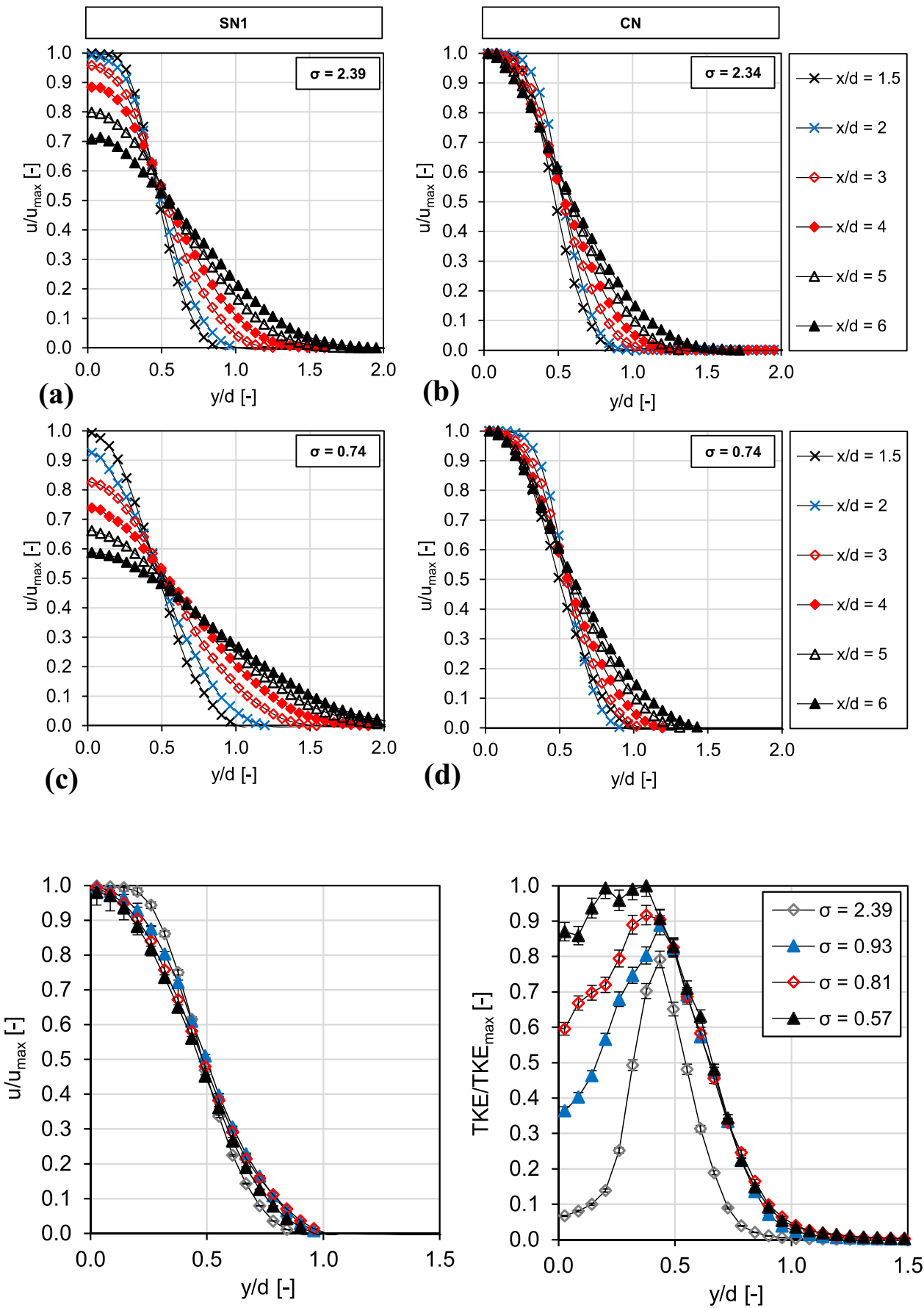

CN shows the typical saddle-back shape. This shape is maintained over a longer axial distance than for SN1, and the jet widens slower compared to the SN1 nozzle. As there is no cavitating regime, with increasing axial distance the radial velocity distribution shows only marginal changes. The jet decay is not promoted by cavitation, and thus, the initial velocity distribution is maintained for a longer distance.

In addition to the velocity profiles, the turbulent kinetic energy (TKE) is used as an approach to quantify the induction of turbulence by cavitation bubbles on the water jet as the TKE values are proportional to $\mathrm{u}_{\mathrm{RMS}}{ }^{2}$ (Roth et al. 2002). As for the 2D velocity data one velocity component is missing for classical TKE calculation, it is assumed that this missing velocity component contains a similar turbulent contribution as the values calculated for the other two velocity components by assuming isotropic turbulence. The radial velocity distribution and the associated TKE distribution for $x / d=1.5$ of nozzle SN1 are plotted in Fig. 12. In 
Fig. 13 Normalised turbulent kinetic energy at $x / d=1.5-6$ of SN1 nozzle at cavitation numbers in the range of $\sigma=0.57-2.39$
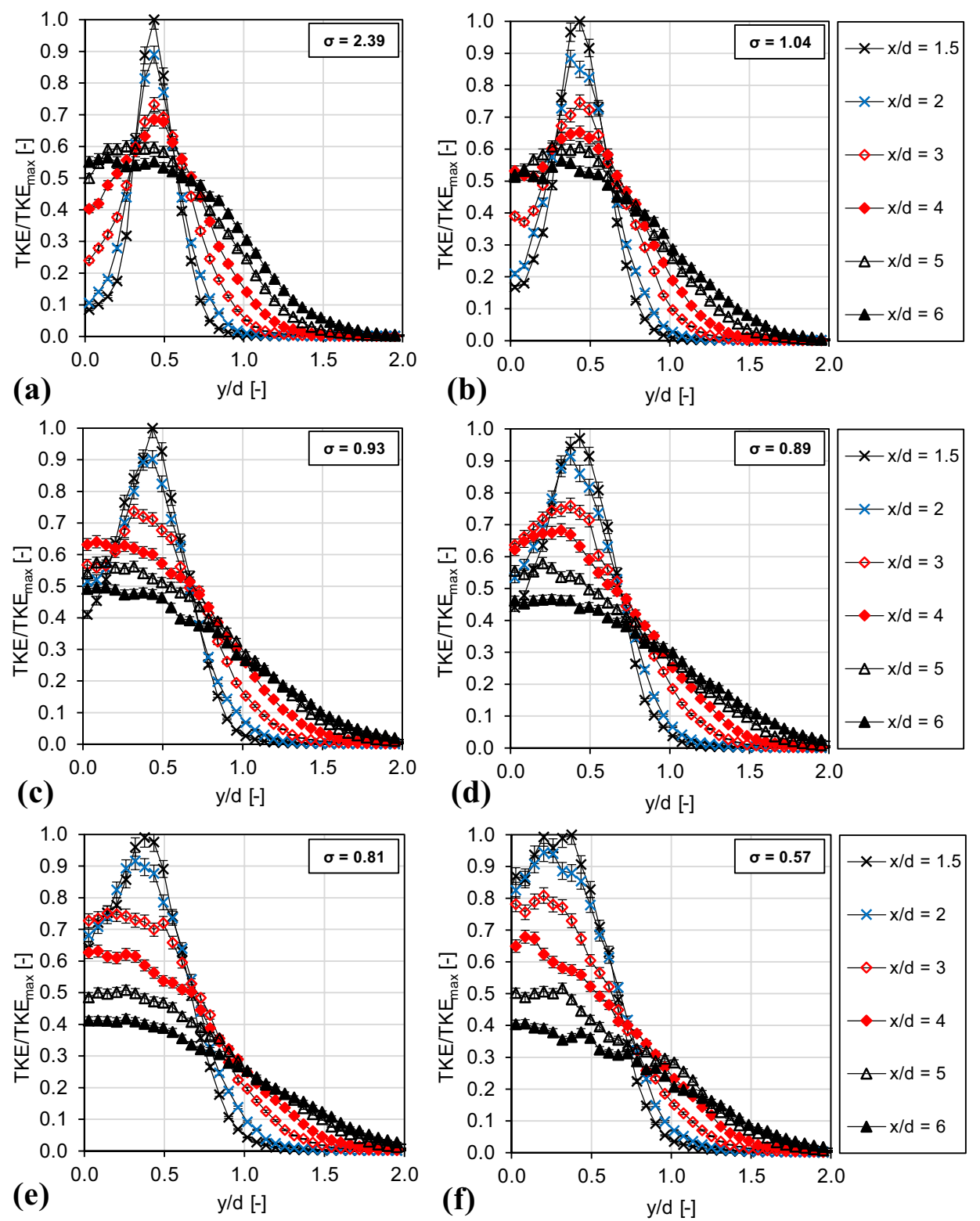

the non-cavitating regime, the TKE profiles show typical low values in the central jet region since the velocity distribution is nearly uniform here. Peaks are visible on the jet edges at about $y / d=0.5$ due to the presence of shear layers and large velocity gradients in that region. With decreasing cavitation number, the pattern of the TKE profiles change. The profile becomes flatter, and although the peak is still at the position with the largest velocity gradient, it is less pronounced. Overall, a significant increase in TKE can be seen with decreasing cavitation number. A more detailed development of the TKE profiles as a function of axial distance from the nozzle and the cavitation number is given in
Fig. 13. In general, and for all cavitation numbers, the TKE values decrease with increasing distance from the nozzle outlet. With decreasing cavitation number, the peak in TKE becomes less significant and the profiles flatten.

The analysis of the jet parameters indicates that there are two regimes: below a recognisable critical value of the cavitation number cavitation occurs inside the used nozzle, whereas above this critical value no cavitation occurs. Both regimes are connected by a short regime of transition where the cavitation bubbles do not fully expand beyond the nozzle body. The results show that cavitation leads to a shorter core length, a larger spreading angle and a larger decay rate. Moreover, 
the velocity profiles are flattened, and turbulence increases. Thus, cavitation leads to a stronger jet decay, and therewith, less kinetic energy is transported to the rock surface to promote erosion of the latter.

\section{Conclusion}

In this work, we investigated the influence of in situ drilling conditions on the fluid mechanics and the development of water jets intended to use for drilling processes. Previous experiments reported in literature were mostly conducted under atmospheric conditions, where the influence of the surrounding fluid and the pressure conditions on the fluid mechanics of the process was neglected. Here, PIV measurements were taken to measure the effect of the surrounding fluid and changing pressure conditions on the flow characteristics of those water jets.

Overall, the results reveal a distinct influence of cavitation under in situ drilling conditions. This influence can be adequately described by the cavitation number. Analysis of the jet parameters and additional flow measurements reveal that there are two regimes of cavitating and non-cavitating nozzle flow. Both regimes are distinguished by a critical cavitation number which is specific for each nozzle. The results indicate that cavitation inside the nozzle leads to a decrease in the potential core length, an increase in the spreading angle and an increase in the jet decay rate. Along with flattened velocity profiles and decreasing TKE peaks in the shear layer region, cavitation leads to a stronger jet decay and consequently to smaller energy transport from the water jet to the rock surface.

For practical reasons, we investigated sapphire-type nozzles because those are the most common type of nozzles applied for jetting now. The sapphire-type nozzles showed an increased jet decay due to cavitation. Due to their similar geometry both sapphire-type nozzles show the similar cavitation characteristics, and the minor differences in the geometry of the sapphire insert from two different manufacturers seem to have no significant influence on the cavitation characteristics. The additionally tested conical nozzle did not show an influence of cavitation on the jet decay, as no cavitation occurred. In future, it might be useful to redesign the sapphire-type nozzles applied in the jetting process to prevent jet decay due to cavitation.

In contrast to previous research, we considered the submerged conditions of the drilling process. The submerged conditions lead to a stronger jet decay than experiments in air and consequently shorten the feasible stand-off distance for drilling. As the effective rock erosion decreases with increasing stand-off distance, the jet decay plays an important role (Pols 1977; Liao et al. 2012; Stoxreiter et al. 2018). The core region of the jet with its high kinetic energy should reach to the rock surface to ensure maximum performance. Moreover, the effective rock erosion decreases with increasing back pressure (Stoxreiter 2018). An increasing back pressure suppresses cavitation inside the nozzle. This might be an indication that cavitation is preferable for rock erosion and that not only the kinetic energy of the jet is decisive.

While there is a scientific discussion whether cavitation is preferable for the drilling process or not, we prove that the occurrence of the latter is depending on the operating conditions and has a great influence on the emerging water jet and thereby on the drilling performance. Whether cavitation is preferable or not for rock erosion must be tested directly through rock sample wear tests, as the granular material properties of the rock themselves play an important role for the erosive effect of the cavitation during the drilling process. The results presented in this work highlight that the predominant cavitation number during the drilling process is a key parameter to control the drilling performance.

Supplementary Information The online version contains supplementary material available at https://doi.org/10.1007/s00348-021-03167-x.

Acknowledgements We thank our project partners Daniel Gradzki and Volker Wittig (Fraunhofer IEG, Bochum, Germany) for the informative discussions how to set up experiments with a relevant relation to the application in the geothermal sector.

Funding Open Access funding enabled and organized by Projekt DEAL. This work is being funded through the "FH-Struktur" venue for universities of applied sciences by the ministry for innovation, science and research of the state of North Rhine-Westphalia, Germany (AZ: 322-8.03.04.02-FH-Struktur 2016/04). The equipment is partly funded from the "FH-Basis" venue for universities of applied sciences by the ministry for innovation, science and research of the state of North Rhine-Westphalia, Germany (AZ: 322-FH-2015_03), and European Union's Horizon 2020 research and innovation programme project "SURE" under grant agreement No. 654662.

\section{Declarations}

Conflict of interest The authors declare that they have no conflict of interest.

Availability of data and material The datasets generated and analysed during the current study are available from the corresponding author on reasonable request.

Open Access This article is licensed under a Creative Commons Attribution 4.0 International License, which permits use, sharing, adaptation, distribution and reproduction in any medium or format, as long as you give appropriate credit to the original author(s) and the source, provide a link to the Creative Commons licence, and indicate if changes were made. The images or other third party material in this article are included in the article's Creative Commons licence, unless indicated otherwise in a credit line to the material. If material is not included in the article's Creative Commons licence and your intended use is not permitted by statutory regulation or exceeds the permitted use, you will need to obtain permission directly from the copyright holder. To view a copy of this licence, visit http://creativecommons. org/licenses/by/4.0/. 


\section{References}

Abramovich GN, Schindel L (2003) The theory of turbulent jets. MIT Press, Cambridge

Brennen CE (1995) Cavitation and bubble dynamics. Oxford Univ. Press, New York

Brook N, Summers DA (1969) The penetration of rock by high-speed water jets. Int J Rock Mech Min. https://doi.org/10.1016/01489062(69)90001-1

Buset P, Riiber M, Eek A (2001) Jet Drilling Tool: Cost-Effective Lateral Drilling Technology for Enhanced Oil Recovery. SPE/ ICoTA Coiled Tubing Roundtable, Society of Petroleum Engineers. https://doi.org/10.2118/68504-MS

Carlomagno GM, Ianiro A (2014) Thermo-fluid-dynamics of submerged jets impinging at short nozzle-to-plate distance: A review. Exp Therm Fluid Sci. https://doi.org/10.1016/j.expthermflusci. 2014.06.010

Cinelli SD, Kamel AH (2013) Novel Technique to Drill Horizontal Laterals Revitalizes Aging Field. In: SPE/IADC Drilling Conference, Society of Petroleum Engineers. https://doi.org/10.2118/ 163405-MS

Dehkoda S, Hood M (2013) An experimental study of surface and subsurface damage in pulsed water-jet breakage of rocks. Int J Rock Mech Min. https://doi.org/10.1016/j.ijrmms.2013.08.013

Donaldson C, Snedeker RS (1971) A study of free jet impingement. Part 1 Mean properties of free and impinging jets. J Fluid Mech. https://doi.org/10.1017/S0022112071000053

Ebrahimi B, He G, Tang Y, Franchek M, Liu D, Picket J, Springett F, Franklin D (2017) Characterization of high-pressure cavitating flow through a thick orifice plate in a pipe of constant cross section. J. Therm. Sci, Int. https://doi.org/10.1016/j.ijthermalsci. 2017.01.001

Gauntner JW, Hrycak P, Livingood JNB (1970) Survery of literature on flow characteristics of a single turbulent jet impinging on a flat plate. NASA Technical Note 19700009658. Washington D.C., NASA

Gradzki DP, Hahn S, Jasper S, Wittig V, Lindken R, Bracke R (2018) High pressure jetting in various rocks - Investigation of failure mechanism and development of drilling process. In: Litvinenko V (ed) Innovation-Based Development of the Mineral Resources Sector: Challenges and Prospects. Taylor et Francis, CRC Press, London

Hood M, Knight GC, Thimons ED (1992) A Review of Jet Assisted Rock Cutting. J Manuf Sci Eng. https://doi.org/10.1115/1.2899772

Hutli E, Nedeljkovic MS, Bonyár A, Légrády D (2017) Experimental study on the influence of geometrical parameters on the cavitation erosion characteristics of high speed submerged jets. Exp Therm Fluid Sci. https://doi.org/10.1016/j.expthermflusci.2016.08.026

Jambunathan K, Lai E, Moss MA, Button BL (1992) A review of heat transfer data for single circular jet impingement. Exp Therm Fluid Sci. https://doi.org/10.1016/0142-727X(92)90017-4

Jasper S, Wittig V, Lindken R (2019): Laser optical investigation of high pressure water jets in submerged reservoir type conditions used for high pressure jetting. In: European Geothermal Congress. The Hague

Jasper S, Hussong J, Lindken R (2017) Visualisation and quantitative analysis of the near nozzle formation and structure of a high pressure water jet in air and water. In: Proceedings ILASS-Europe 2017. Valencia

Leach SJ, Walker GL, Smith AV, Farmer IW, Taylor G (1966) Some aspects of rock cutting by high speed water jets (and discussion). Trans. R. Soc. A, Philos. https://doi.org/10.1098/rsta.1966.0051

Liao H, Li G, Yi C, Niu J (2012) Experimental study on the effects of hydraulic confining pressure on impacting characteristics of jets. Atomiz Spr. https://doi.org/10.1615/AtomizSpr.2012005126

Macian V, Payri R, Margot X, Salvador FJ (2003) A CFD analysis of the influence of diesel nozzle geometry on the inception of cavitation. Atomiz Spr. https://doi.org/10.1615/AtomizSpr.v13. i56.80

Martin H (1977) Heat and Mass Transfer between Impinging Gas Jets and Solid Surfaces. In: James P, Hartnett und Thomas F. Irvine, (eds) Advances in heat transfer. Academic Press, New York

Matthujak A, Kasamnimitpron C, Sriveerakul T (2020) Comparative visualized investigation of impact-driven high-speed liquid jets injected in submerged water and in ambient air. J Vis. https://doi. org/10.1007/s12650-020-00640-3

Momber AW (2004) Aggregate liberation from concrete by flow cavitation. Int J Miner Process. https://doi.org/10.1016/j.minpro.2003. 10.004

Momma T, Lichtarowicz A (1995) A study of pressures and erosion produced by collapsing cavitation. Wear. https://doi.org/10.1016/ 0043-1648(95)07144-X

Ohrn TR, Senser DW, Lefebvre AH (1991) Geometrical effects on discharge coefficients for plain-orifice atomizers. Atomiz Spr. https:// doi.org/10.1615/AtomizSpr.v1.i2.10

Örley F, Trummler T, Hickel S, Mihatsch MS, Schmidt SJ, Adams NA (2015) Large-eddy simulation of cavitating nozzle flow and primary jet break-up. Phys Fluids. https://doi.org/10.1063/1.4928701

Payri R, Margot X, Salvador FJ (2002) A Numerical Study of the Influence of Diesel Nozzle Geometry on the Inner Cavitating Flow. In: SAE Technical Paper Series. SAE 2002 World Congress \& Exhibition. https://doi.org/10.4271/2002-01-0215

Pols AC (1977) High-Pressure Jet-Drilling Experiments in Some Hard Rocks. J Pressure Vessel Technol. https://doi.org/10.1115/1.3454541

Pope SB (2000) Turbulent flows. Cambridge University Press, Cambridge

Quinn WR, Militzer J (1988) Experimental and numerical study of a turbulent free square jet. Phys Fluids. https://doi.org/10.1063/1. 867007

Ragab AM, Kamel AM (2013) Radial Drilling Technique for Improving Well Productivity in Petrobel -Egypt. In: North Africa Technical Conference and Exhibition. North Africa Technical Conference and Exhibition, Society of Petroleum Engineers. https://doi. org/10.2118/164773-MS

Reinsch T, Paap B, Hahn S, Wittig V, van den Berg S (2018) Insights into the radial water jet drilling technology - Application in a quarry. J Rock Mech Geotech Eng. https://doi.org/10.1016/j. jrmge.2018.02.001

Ross D (2013) Mechanics of Underwater Noise. Elsevier Science, Burlington

Roth H, Gavaises M, Arcoumanis C (2002) Cavitation Initiation, Its Development and Link with Flow Turbulence in Diesel Injector Nozzles. In: SAE Technical Paper Series. SAE 2002 World Congress \& Exhibition. https://doi.org/10.4271/2002-01-0214

Sou A, Hosokawa S, Tomiyama A (2007) Effects of cavitation in a nozzle on liquid jet atomization. INT J HEAT MASS TRAN. https:// doi.org/10.1016/j.ijheatmasstransfer.2006.12.033

Soyama H, Yanauchi Y, Sato K, Ikohagi T, Oba R, Oshima R (1996) High-speed observation of ultrahigh-speed submerged water jets. Exp Therm Fluid Sci. https://doi.org/10.1016/0894-1777(95) 00124-7

Stoxreiter T, Martin A, Teza D, Galler R (2018) Hard rock cutting with high pressure jets in various ambient pressure regimes. Int J Rock Mech Min. https://doi.org/10.1016/j.ijrmms.2018.06.007

Westerweel J, Scarano F (2005) Universal outlier detectin for PIV data. Exp Fluids. https://doi.org/10.1007/s00348-005-0016-6

Young FR (1989) Cavitation. McCraw-Hill, London

Publisher's Note Springer Nature remains neutral with regard to jurisdictional claims in published maps and institutional affiliations. 